\title{
MANIERISMO EN LA POÉTICA POSTNOVISIMA ESPAÑOLA
}

El término manierismo designa la época artística que en la historia del arte enlaza el Renacimiento con el Barroco; pero también marca una poética, un estilo artístico, ciertos procedimientos artísticos y literarios que pueden aparecer antes o después de la época históricamente determinada como manierista. Esta segunda definición del término es consecuencia de relaciones particulares que el manierismo cultiva hacia la realidad, la tradición y la literatura. De este modo, los temas y los motivos, como también el estilo y la composición manieristas aparecen en varias literaturas del siglo $\mathrm{XX}$, tanto en prosa como en poesía.

El camino recorrido por la literatura española en los últimos años, se ramifica en varias vertientes poéticas, de acuerdo con el posmodernismo que fortifica la pluralidad expresiva. Prácticamente no se ha abierto ninguna onda nueva, pero se han profundizado las existentes. En la poesía el carácter plural de las últimas generaciones poéticas y la falta de una estética dominante son los tópicos más frecuentemente repetidos por la critica. Ironizaba Julio Llamazares al respecto en la antologia Postnovísimos de Luis Antonio de Villena:

"Sorprende comprobar cómo la pasión onanista de los críticos, roto el andamiaje conceptual y pedagógico de las tendencias, las generaciones y los grupos, ha llegado al descubrimiento de la diversidad como único denominador común entre los poetas españoles menos viejos. Esto es: la ausencia de parecidos como elemento aglutinador, la inexistencia como sustancia, la negación como afirmación"l.

Ya la generación de los ochenta ha sido calificada generalmente de continuista. Este término no hay que tomarlo como una acusación, aunque la crítica lo ha empleado a veces con connotaciones negativas ${ }^{2}$. El nuevo subjetivismo lírico (Andrés Trapiello con Las tradiciones, 1982 y La vida fácil, 1985) o la otra sentimentalidad (con El jardin extranjero, 1983 de Luis Garcia Montero), el neosurrealismo (prosa poética de Julio Llamazares o De una niña de provincias que se vino a vivir en un Chagall, 1981 de Blanca Andreu), el culturalismo, el eclecticismo, el prosaísmo (Sobre las circunstancias, 1981 de Juan Antonio Goytisolo) o poesía de sincera elementalidad (Asamblea de máscaras de Mariano Roldán en $1981^{3}$ ) son sólo algunas entre numerosas vertientes poéticas actuales. Este fragmentarismo podría relacionarse con la cosmovisión (Weltanschauung) descompuesta de la actualidad. El hombre percibe la realidad existencial por partes desconectadas que luego las proyecta también sobre la realidad literaria.

Una de las estéticas postnovisimas es la que entiende la realidad y la tradición de la manera manierista y utiliza en sus procesos poéticos los procedimientos que pueden ser calificados de tipo manierista. Esos casos engendran actitudes satíricas, irónicas y subversivas, creando de este modo un juego de múltiples perspectivas. Las diversas maneras de modificar o subvertir convenciones y textos tradicionales revelan un deseo de los poetas contemporáneos de cuestionar y rehacer la realidad actual.

Fernando de Villena declara en el prólogo de su primer libro Pensil de rimas celestes:

"Autores de los siglos XVI y XVII buscaron abrigo a la hora de escribir sus deliciosos poemas en la excelsa luz que desprendian (y desprenden) las antorchas (digo cálamos) de aquellos gigantes de la antigüedad: Ovidio, Píndaro, Horacio, Virgilio [...] desde este prólogo y desde las rimas que siguen preconizo un nuevo manierismo, siendo los modelos, no ya unos clásicos tan lejanos como los grecolatinos, sino los no menos dignos escritores españoles de los dorados siglos"4. 
Algunos poetas reivindican los procedimientos literarios establecidos en el pasado con ironía, a veces hasta el punto de que el pastiche se convierte decididamente en parodia. Utilizan alusiones literarias, imágenes elaboradas, un vocabulario cuidadosamente seleccionado, reviven la métrica clásica -sonetos, liras, silvas-, tan olvidada por las generaciones anteriores. El resultado es un mundo ambiguo, posmoderno, en el que la intensa sensualidad coexiste con su parodia.

Umberto Eco resume la actitud básica del posmodernismo: "La respuesta posmoderna a lo moderno consiste en reconocer que el pasado, ya que no se puede realmente destruir, porque su destrucción conduce al silencio, debe ser revisado: pero con ironia, no inocentemente" 5 . La estética posmoderna también desmantela críticamente la moralidad del orden establecido y se replantea los moldes poéticos anteriores desde una ambigua actitud paródica que simultáneamente acepta y subvierte sus propios modelos. Este replanteamiento puede encuadrarse en las bases de la posmodernidad, como reacción frente al arte moderno establecido y agotado, abogando por una reevaluación crítica o metaliteraria de las formas poéticas. Como resultado de esta reexaminación se redescubren las posibilidades de elementos lúdicos en la literatura posmoderna, cruzándose asi las mismas fronteras que convencionalmente han venido distiguiendo un arte culto superior de un arte popular de entretenimiento.

"Esta tensión generada por la confrontación de la crónica y la metaficción, la representación realista y la auto-reflexividad, historia y formalismo, arte elevado y arte popular, parodia y política es el rasgo que define, en última instancia, la obra posmoderna: una suerte de complicidad y crítica, de reflexividad e historicidad, que inscribe y, a su vez, subvierte las convenciones e ideologías de las fuerzas culturales y sociales dominantes del mundo occidental del siglo $\mathrm{XX}^{\prime \prime}$.

En las últimas décadas del siglo XX, en una época de transición, ha llegado el momento cuando hay que volver hacia el pasado, hacia la tradición, pero no de una manera obligatoria, sino libre y voluntariamente. Una de estas vueltas hacia el pasado en el arte, o sea en la literatura, es también regreso hacia la poética manierista que ella también surgió en su momento histórico en una sociedad de transición.

El manierismo como etapa de transición entre Renacimiento y Barroco (Hauser, 1965; Hatzfeld, 1964), o como concepto ideológico (Curtius, 1961), obligó a los especialistas a replantear el problema de los periodos artísticos.

El Manierismo se relaciona estrechamente con el Barroco. Con ellos suelen describirse fenómenos temporalmente muy cercanos, por eso muchas veces aparecen juntos o incluso se sobreentienden. Ernst Robert Curtius en su obra Europäische Literatur und Lateinisches Mittelalter ${ }^{7}$ define el manierismo como conjunto de procedimientos estilísticos que proceden de una determinada situación literaria y de una determinada manera de entender la literatura. Según Curtius el manierismo aparece cuando una época clásica se encuentra en crisis o en su cenit y se manifiesta como complicación de expresión literaria; los autores no confian en la expresión clara y directa, dudan de la función social de la literatura que por consecuencia se convierte en esotérica y de élite.

Por consiguiente, hay que palntearse la pregunta impuesta por si misma: ¿es aceptable en la historia literaria la idea del ciclismo? o sea, ¿se repite todo el tiempo una misma crisis que se manifiesta siempre de la misma manera? René Wellek, a diferencia de Curtius, define el barroco como estilo y también como ideología.

Si se considera que el manierismo (o el barroco) puede determinarse como estilo, ya se ha hecho la selección entre lo histórico y lo tipológico en favor de lo tipológico porque es evidente que a lo largo de la historia literaria los estilos se repiten. Si por otra parte se cree que el manierismo (o el barroco) es una ideología, el concepto por el cual se ha decidido es de tipo histórico, porque 
las ideologías se relacionan con las situaciones socio-históricas, y éstas por su parte son fenómenos únicos que nunca pueden repetirse de una manera exactamente igual.

El problema esencial que se plantea no es si el manierismo y el barroco forman dos estilos y dos ideologías, o un estilo y dos ideologías, o una ideología y dos estilos, sino si el manierismo y el barroco corresponden a dos distintas poéticas o a una sola. De acuerdo con lo dicho podriamos concluir de que se trata de dos poéticas diferentes (ver los textos de Heinrich Wölfflin ${ }^{8}$ y Arnold Hauser $^{9}$ ). Los dos períodos comparten algunas semejanzas tanto ideológicas como estilisticas, $\sin$ embargo cada periodo tiene su propia poética - en la poética manierista es importante el contenido, mientras que en la barroca cuenta sobre todo el estilo.

Según el criterio histórico, es necesario limitar el uso del manierismo y del barroco a los siglos XVI y XVII. Sin embargo, en distintas épocas literarias pueden aparecer estilo, composición, forma, elaboración del contenido,... manieristas o barrocos. Eso ocurre en el siglo XX, concretamente en la época contemporánea del posmodernismo. Por eso, no se puede utilizar el término manierismo, sino hay que recurrir a otros términos: el nuevo manierismo como propone Fernando de Villena, o manera manierista.

El Manierismo también tiene que relacionarse con el Renacimiento. En la segunda parte del siglo XVI ocurrieron algunos acontecimientos culturales que afectaron mucho la literatura. Apareció el protestantismo y Europa dejó de ser uniforme. Se quebró la imagen geocéntrica del universo, entonces la relación entre la literatura y la cosmovisión a partir de entonces ya no fue tan natural y autoritaria como en la época de Dante. Una vez quebrados los puntos de referencia firmes en la vida del hombre, éste cae en crisis. Como consecuencia de un profundo cambio que se produce en las más diversas manifestaciones de la vida y del arte, se derrumban muchas certidumbres en las que el hombre se había apoyado hasta aquel entonces.

Como la literatura se encuentra en esa sociedad de considerables cambios sin soporte ideológico, ella también cae en un vacío, lanzándose a buscar referencias en las fuerzas oscuras e irracionales de la existencia humana, inclinándose hacia la negación del arte clásico, hacia las complicaciones estilísticas y hacia el jugueteo de todo tipo.

En una situación parecida se encuentra también la literatura contemporánea, un poco perdida en la multitud de posibilidades estéticas dentro de una cultura polifacética y en continuo movimiento. Los escritores en tales situaciones siempre reaccionan de un modo parecido y especifico. Simplificando sus posturas, es posible decir que mucho más que en las épocas en las que la ideología determina claramente la poética, empiezan a ocuparse de sí mismos y de su propia labor literaria. Por eso reflexionan sobre su propia posición creativa y sobre la función transcedental de la literatura, experimentando con ella y averiguando sus posibilidades expresivas.

Las obras literarias en tales condiciones reflexionan mucho sobre la naturaleza de la literatura, sobre sus límites, sus alcances y sus posibilidades. La literatura es consciente de su propio convencionalismo que frecuentemente lo desmitifica con distintas técnicas. En breve, las convenciones literarias ya no representan un conjunto de reglas que el escritor, en su ambición de crear una buena obra literaria, tiene que seguirlas sino éstas se convierten en el tema mismo de la obra literaria.

Esta inclinación de que la literatura se convierta en metaliteratura, o sea que tome a si misma como tema literario, es típica para la poética manierista y se manifiesta dentro de las relaciones que la literatura mantiene hacia la tradición, hacia la realidad y hacia si misma.

La tradición se convierte en la poética manierista en un tema importantísimo. Mientras la literatura renacentista tenía una relación afirmativa hacia la tradición, respetando la regla de la imitación, a partir de la segunda mitad del siglo XVI la literatura concibe su relación hacia la tradición de 
un modo incierto, lleno de intertextualidad ${ }^{10}$. Tal tipo de relaciones podríamos llamar metatextualidad que se manifiesta también en algunos ejemplos de la poesia española postnovísima. Ejemplo:

Ni Virgilio, ni Góngora, ni Baudelaire, ni Dante.

Un poeta menor en rima consonante

O verso casi libre, porque no hay libertad

Ni para la belleza ni para la verdad.

Que por no traicionar una vieja costumbre

De las pródigas noches de mal distinta lumbre,

He escuchado igualmente al ruiseñor y al cuervo

Por que ningún matiz le faltara a mi acervo,

Y que cuando la tarde deja morir su luz

Hablo con Rabelais y San Juan de la Cruz ${ }^{11}$.

Los escritores manieristas toman en consideración también la relación compleja entre la literatura y la realidad, o sea, de la realidad en la literatura y de la literariedad en la realidad. La relación entre la realidad y literatura es siempre muy problemática. Aun más en los períodos de transición cuando el papel de la literatura en la realidad es muy indefinido: algunas veces se considera que la realidad es tan ficcional como la literatura, otras que la literatura es tan real como la realidad misma. Cervantes, por ejemplo, en su Don Quijote cuenta la historia de un hombre que mezcla entre sí la realidad y la literatura, que trata de entender la literatura como una verdadera descripción de la realidad y la iguala a la descrita en los libros. El efecto principal de tal mezcla es la relativización tanto de la literatura como de la realidad, se trata de la metarealidad en la literatura. Ejemplo:

Del más dulce artificio de la naturaleza

Sé decir cómo acaba porque sé cómo empieza,

$\mathrm{Y}$ aunque mil veces supe de su amargo final

No renuncié a los frutos de sus flores del mal,

Cuando en mi adolescencia fui precoz jardinero

En la cálida sombra de su fruto primero

Y más tarde en mi cómplice reino de juventud,

Sin seducirme el vicio, seduje a la virtud.

Hasta que casi ya sentada la cabeza

Supe del artificio hacer naturaleza ${ }^{12}$.

A parte de la relativización de la tradición y de la realidad, la poética manierista problematiza también su propio significado, las posibles interpretaciones del texto. Como en la vida humana se han derrumbado muchísimas certidumbres, -filosóficas, religiosas, ideológicas- que en otros periodos garantizaban las interpretaciones unánimes, los escritores manieristas y las del nuevo manierismo se dan cuenta de que tanto la literatura anterior como la actual pueden ofrecer distintas interpretaciones, de que no hay explicaciones que sean únicas, exhaustivas y definitivas. Por eso se sienten obligados de dar ciertas instrucciones al lector para que éste no falsifique demasiado el significado estético - a veces discuten sobre el arte en general o sobre determinados aspectos del arte $^{13}$, a veces presentan su propia interpretación ${ }^{14}$. Entonces, la literatura trata a sí misma e introduce en su propio terreno la metainterpretación.

De las múltiples formas de decir la verdad

Acaso yo prefiera la de la ambigüedad.

No saber que se dice lo que quizá se ha dicho

Si con la voluntad o si con el capricho, 
Abandonarse al vértigo de buscar la raiz

$Y$ encontrar que la savia es cuestión de matiz,

Que de lo que se impone como febril presagio

No saber lo que es fruto del ingenio o del plagio

Y dejar al albur del discreto lector

Dónde acaba lo dado por que empiece el autor ${ }^{15}$.

Algunos poetas contemporáneos en su empeño poético del nuevo manierismo parodian los textos de los autores clásicos españoles. Luis Garcia Montero, para describir en su Rimado de ciudad (1984) ciertos marginales ambientes urbanos, parte de una nueva versión de las Soledades de Góngora; la elegía de Jorge Manrique se transforma en Coplas a la muerte de su colega. Una gran sensibilidad ante la realidad actual, ante los niveles y las formas del discurso poético posmoderno sirve de base a la obra del poeta vasco Jon Juaristi. El titulo de su Diario del poeta recién cansado (1985) recuerda el de Juan Ramón Jiménez. Con su actitud compleja e irónica presenta su poesía en forma de sermones, de nostálgicas obras líricas, de descripciones y de versiones de otros poemas. La sátira literaria y social se combinan magistralmente en el poema La casada infiel, parodiando uno de los romances más sagrados de Federico Garcia Lorca. El protagonista gitano de Lorca se convierte en el poema de Juaristi en un protagonista vasco, el marido en un terrorista de Herri Batasuna y en vez de un costurero el regalo es una "icurriña". Con estos cambios Juaristi por una parte parodia la exagerada afectación del romance lorquiano y por otra el extremismo y terrorismo vasco.

Parodiar alusiones literarias clásicas con el fin de revalorar las relaciones sociales es también tema preferido por Ana Rosetti. Sus textos dejan campo abierto en sus interpretaciones, en este sentido posmodernas. Igualmente subversivos son los textos de Amparo Amorós, entre otros su Quevediana (1988). El poemario está compuesto de una serie de sonetos que se enfrentan a textos poéticos de Quevedo con el fin de satirizar diversos tipos de la realidad cotidiana y situaciones en las que nos encontramos en nuestra vida diaria: un encuentro literario, un critico, un autor que trabaja para una revista, etc. En Soneto burlesco a un Apolo para necias acaloradas Amorós parte del poema satírico de Quevedo $A$ un hombre de gran nariz. El poema es una parodia en varios niveles, de diferentes discuros y convenciones - entre otros, del texto de Quevedo, de la lectura convencional de su texto como insinuación sexual, de la poesía de alusiones sexuales en general y en particular de la que es escrita por mujeres. El poema tiene varias lecturas y funciona como un estímulo social para las reacciones del lector.

Mutatis mutandis es, por lo tanto, el lema válido para toda la literatura de transición, igual en el pasado como en la actualidad.

"Todo discurso forma parte de una historia de discursos: todo discurso es la continuación de discursos anteriores, la cita explícita o implícita de textos previos. Todo discurso es susceptible, a su vez, de ser injertado en nuevos discursos, de formar parte de una clase de textos, del cuerpo textual de una cultura", afirma Graciela Reyes ${ }^{16}$.

Esta concepción de la intertextualidad - transtextualidad como la denomina Gérard Genette ${ }^{17}$, condiciona el discurso poético posmoderno, en el que aparecen la alusión, la transcripción, la parodia, la citación directa o indirecta. Las imágenes sorprendentes y las notas humorísticas en la poesía producen percepciones agudas de la realidad moderna. Las diversas maneras de modificar convenciones y textos clásicos revelan un deseo de los poetas españoles contemporáneos de cuestionar y rehacer la realidad actual. Aunque estilisticamente continuista, la originalidad y el valor de la poesía española postnovisima reside precisamente en esta variedad de temas, formas, tonos y perspectivas poéticos. 
1 Luis Antonio de Villena: Postnovisimos, Madrid, Visor 1986.

2 La ruptura pos si misma no representa ninguna garantía para la calidad poética. Garcilaso, por ejemplo, rompió con la tradición cancioneril del siglo XV y es un gran poeta, pero también lo son Fray Luis de León o San Juan de la Cruz que continuaron la tradición italianizante.

3 Los últimos versos de su Testamento siguiente critican la ornamentación verbal dominante en la poesía española desde tiempos de los novísimos.

4 Fernando de Villena: Pensil de rimas celestes, Barcelona, Ambito 1980.

5 Umberto Eco: Postcript to The Name of the Rose, Orlando, Harcourt 1984, p. 67.

6 Linda Hutcheon: A Poetics of Postmodernism: History, Theory, Fiction, New York \& London 1996?.

7 Ernst Robert Curtius: Literatura europea y la Edad Media latina, Madrid, FCE 1995.

8 Heinrich Wölfflin: Renesansa i barok (Renaissance und Barock), Zagreb, ŠK 1977.

9 Arnold Hauser: Mannerism, The Crisis of the Renaissance and the Origin of Modern Art, London 1965.

10 Julia Kristeva considera que todo texto es como un mosaico de citas, todo texto es absorción y transformación de otro texto y cada lenguaje poético debe leerse, por lo menos, como doble.

Kristeva, Julia: El texto de la novela, Barcelona, Lumen $1981^{2}$.

11 Los ejemplos representados son del poeta contemporáneo Francisco Castaño, de su Libro de las maldades, Madrid, Hiperión 1992, p. 17.

12 Ibid., p. 19.

13 Por ejemplo, el discurso de actores en Hamlet.

14 El ejemplo extremo es el soneto famoso de Lope de Vega La niña de plata (“Un soneto me manda hacer Violante...) como ejemplo ilustrativo de cómo debe componerse un soneto.

15 Francisco Castaño, op. cit., p. 18.

16 Graciela Reyes: Polifonía textual. La citación en el relato literario, Madrid, Gredos 1984, pp. $42-43$.

17 Gérard Genette: Palimpsestos. La literatura en segundo grado, Madrid, Taurus 1989.

\section{Bibliografia}

Castaño, Francisco: Libro de las maldades, Madrid, Hiperión 1992

Curtius, Ernst Robert: Literatura europea y la Edad Media latina, Madrid, FCE 1995

De Villena, Luis Antonio: Postnovisimos, Madrid, Visor 1986

De Villena, Fernando: Pensil de rimas celestes, Barcelona, Ambito 1980

Eco, Umberto: Postcript to The Name of the Rose, Orlando, Harcourt 1984

Flaker, Aleksandar - Škreb, Zdenko: Stilovi i razdoblja, Zagreb 1964

Genette, Gérard: Palimpsestos. La literatura en segundo grado, Madrid, Taurus 1989

Hauser, Arnold: Mannerism, The Crisis of the Renaissance and the Origin of Modern Art, London 1965

Hutcheon, Linda: A Poetics of Postmodernism: History, Theory, Fiction, New York \& London 19967

Kalenić Ramšak, Branka: Posmodernismo como fenómeno cultural y literario, Actas del V Congreso "Cultura Europea", Pamplona 1998

Kristeva, Julia: El texto de la novela, Barcelona, Editorial Lumen 1981

Reyes, Graciela: Polifonia textual. La citación en el relato literario, Madrid, Gredos 1984

Wölfflin, Heinrich: Renesansa i barok (Renaissance und Barock), Zagreb, ŠK 1977

\section{MANIRIZEM V SODOBNI ŠPANSKI KNJIŽEVNOSTI - POETIKA "POSTNOVISIMA"}

Termin manirizem $\mathrm{v}$ zgodovini umetnosti označuje obdobje, ki je povezano $\mathrm{z}$ renesanso in barokom, vendar označuje tudi določeno poetiko, v književnosti nekatere značilnosti, ki se lahko pojavijo časovno tudi pred ali po zgodovinskem manierističnem obdobju. $\mathrm{V}$ tem primeru nimamo več opravka $\mathrm{z}$ manirizmom temveč $\mathrm{z}$ manirističnim načinom obravnavanja književnosti, z manirističnim odnosom do stvarnosti in do tradicije. V sodobnem postmodernem obdobju, za katerega je značilna odostnost dominantne umetniške usmeritve, spogledovanje $s$ preteklostjo in dovzetnost za med seboj povsem različne umetniške tendence, se pojavlja tudi novi manirizem. V sodobni španski književnosti oz. poeziji ga imenujejo poetika "postnovisima". Članek skuša na primerih iz sodobne španske poezije izluščiti nekaj pomembnih značilnosti maniristične poetike in opredeliti njen odnos do preteklosti, stvarnosti in umetnosti oz. književnosti. 